\title{
Article \\ Antibacterial Photodynamic Inactivation of Fagopyrin F from Tartary Buckwheat (Fagopyrum tataricum) Flower against Streptococcus mutans and Its Biofilm
}

\author{
Jaecheol Kim ${ }^{1,2}$, Suna Kim ${ }^{3}$, Kiuk Lee ${ }^{1}$, Ryun Hee Kim ${ }^{1,2}$ and Keum Taek Hwang ${ }^{1,2, *(D)}$ \\ 1 Department of Food and Nutrition, Research Institute of Human Ecology, Seoul National University, \\ Seoul 08826, Korea; ddeol@snu.ac.kr (J.K.); leku@snu.ac.kr (K.L.); ryunheekim@snu.ac.kr (R.H.K.) \\ 2 BK21 FOUR Education and Research Team for Sustainable Food \& Nutrition, Seoul National University, \\ Seoul 08826, Korea \\ 3 Division of Human Ecology, College of Natural Science, Korea National Open University, Seoul 03078, Korea; \\ ksuna7@mail.knou.ac.kr \\ * Correspondence: keum@snu.ac.kr
}

check for

updates

Citation: Kim, J.; Kim, S.; Lee, K.; Kim, R.H.; Hwang, K.T. Antibacterial Photodynamic Inactivation of

Fagopyrin F from Tartary Buckwheat (Fagopyrum tataricum) Flower against Streptococcus mutans and Its Biofilm. Int. J. Mol. Sci. 2021, 22, 6205. https:// doi.org/10.3390/ijms22126205

Academic Editors: Antonino Mazzaglia Angela Scala and Enrico Caruso

Received: 17 May 2021

Accepted: 3 June 2021

Published: 8 June 2021

Publisher's Note: MDPI stays neutral with regard to jurisdictional claims in published maps and institutional affiliations.

Copyright: (c) 2021 by the authors. Licensee MDPI, Basel, Switzerland. This article is an open access article distributed under the terms and conditions of the Creative Commons Attribution (CC BY) license (https:/ / creativecommons.org/licenses/by/ $4.0 /)$

\begin{abstract}
The objective of this study was to determine reactive oxygen species (ROS) produced by fagopyrin F-rich fraction (FFF) separated from Tartary buckwheat flower extract exposed to lights and to investigate its antibacterial photodynamic inactivation (PDI) against Streptococcus mutans and its biofilm. ROS producing mechanisms involving FFF with light exposure were determined using a spectrophotometer and a fluorometer. S. mutans and its biofilm inactivation after PDI treatment of FFF using blue light (BL; $450 \mathrm{~nm}$ ) were determined by plate count method and crystal violet assay, respectively. The biofilm destruction by ROS produced from FFF after exposure to BL was visualized using confocal laser scanning microscopy (CLSM) and field emission scanning electron microscope (FE-SEM). BL among 3 light sources produced type 1 ROS the most when applying FFF as a photosensitizer. FFF exposed to BL $\left(5\right.$ and $\left.10 \mathrm{~J} / \mathrm{cm}^{2}\right)$ significantly more inhibited S. mutans viability and biofilm formation than FFF without the light exposure $(p<0.05)$. In the PDI of FFF exposed to $\mathrm{BL}\left(10 \mathrm{~J} / \mathrm{cm}^{2}\right)$, an apparent destruction of $S$. mutans and its biofilm were observed by the CLSM and FE-SEM. Antibacterial PDI effect of FFF was determined for the first time in this study.
\end{abstract}

Keywords: Tartary buckwheat; fagopyrin F; fagopyrin; photosensitizer; ROS; photodynamic therapy

\section{Introduction}

Buckwheat plants contain protofagopyrins, which are converted to fagopyrins when the plant extract is exposed to light [1]. Both protofagopyrins and fagopyrins belong to naphthodianthrone and act as photosensitizers (PS) [1,2]. Protofagopyrins were converted to fagopyrins most rapidly when exposed to blue light (BL) and fluorescence light, and fagopyrins maintained a stable structure even when exposed to various light sources for $8 \mathrm{~h}$ [3]. Hypericin, one of naphthodianthrones structurally similar to fagopyrins and protofagopyrins, has been studied as a PS for various photodynamic effects including antibacterial effects [4-6]. Benković et al. reported the structural characteristics of fagopyrins, which are similar to hypericin [1]. Fagopyrins and hypericin have the same absorbance spectra (maximum absorbance: $590 \mathrm{~nm}$ ) [1,3]. Also, fluorescence of fagopyrins and hypericin was detected at an excitation wavelength of $330 \mathrm{~nm}$ and emission wavelength of $590 \mathrm{~nm}$ [1,7-9]. However, to the best of our knowledge, photodynamic effects of fagopyrins and protofagopyrins have not yet been reported. Tartary buckwheat flowers (TBF) are richer in fagopyrins (protofagopyrins) than the other parts of the buckwheat plant (e.g., stems, leaves, flowers, groats, and hulls), regardless of the cultivar type $[1,3,7,9]$. Six fagopyrins $(\mathrm{A}-\mathrm{F})$ were reported to exist in buckwheat plants with fagopyrins $\mathrm{A}$, E, and $\mathrm{F}$ identified $[1,8]$. In addition, Kim and Hwang reported that fagopyrin F (FF) accounted for more than $93 \%$ of total fagopyrins in TBF extracts exposed to light [9]. Given these results, 
in this study, we prepared FF-rich fraction (FFF) separated from the TBF extract exposed to lights and further determined photodynamic effect of the FFF.

Photodynamic therapy (PDT) is a clinical treatment against harmful microorganisms, tumors, viruses, and parasites and is based on the photochemical reaction of PS [10,11]. PS molecules absorb light of a specific wavelength initiating reactive oxygen species (ROS) production, which leads to selective cellular or tissue destruction (Figure 1) [10-12]. After exposure to light, energy from the triplet excited state of the PS is transferred to two ROS production mechanisms [10-13]. In the type 1 ROS photodynamic mechanism, the PS transfers hydrogen or electrons to biomolecules from its surroundings. This process initially produces ROS in the form of superoxide anion radicals $\left(\mathrm{O}_{2}{ }^{-}-\right.$, which further generates other ROS molecules, such as hydrogen peroxide and hydroxyl radicals, inside the cell [10-13]. In the type 2 ROS photodynamic mechanism, energy from the triplet excited state of the PS is directly transferred to oxygen molecules in the ground energy state $\left({ }^{3} \mathrm{O}_{2}\right)$. This process produces singlet oxygen $\left({ }^{1} \mathrm{O}_{2}\right)$, which exhibits strong oxidative properties [10-13].

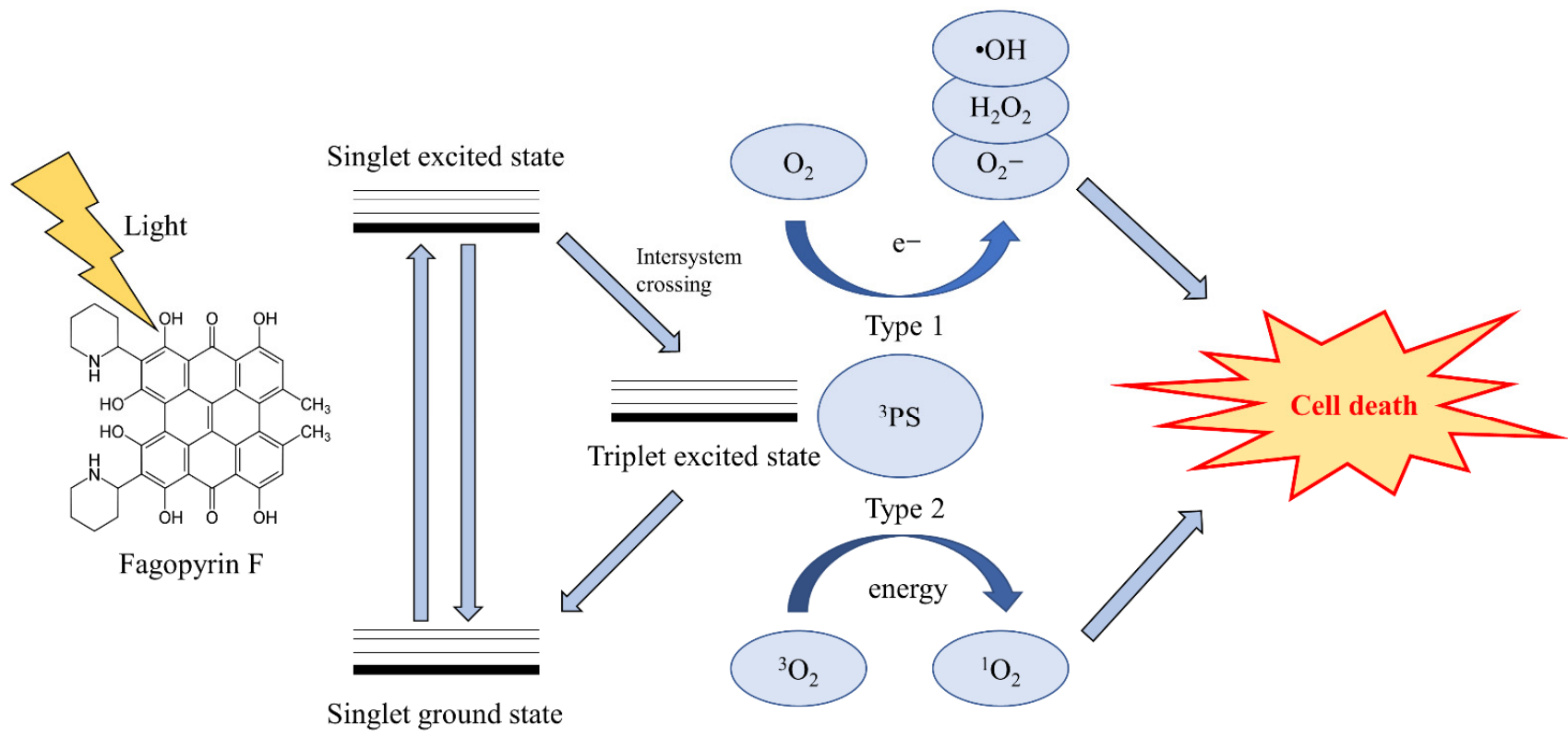

Figure 1. Structure of fagopyrin $\mathrm{F}$ and schematic illustration of photodynamic therapy.

One of the most widely studied PDT applications is antibacterial photodynamic inactivation (PDI), which can be applied to several bacterial species. Among possible treatment sites for PDI, oral cavity is exposed outside, not inside the human body; thus, PDI can be directly applied to the oral cavity to inactivate various harmful bacteria. Since the PDI method for the oral cavity is simple, and PDI does not cause antibiotic resistance to harmful bacteria in the oral cavity, PDI has been studied fairly extensively for eliminating harmful bacteria in the oral cavity [14-16]. Streptococcus mutans is a gram-positive bacterium that causes dental erosion by forming biofilm [16]. Biofilm, a complex of bacteria and their secondary metabolites (e.g., sugars, acids, and glucans), forms a layer on the surface of the teeth [16]. Various PS have been used to inactivate harmful oral bacteria. Among them, curcumin and hypericin originated from food sources, are typical PS against harmful oral bacteria $[4,17-19]$. PDI of curcumin or hypericin as a PS destroyed most $S$. mutans (over 99\%) and inhibited their biofilm formation $[4,17,18]$. Application of PDI to S. mutans has been studied in terms of biofilm inactivation and destruction, and the treatment effect of PDI has been mainly confirmed using spectrometer and microscope techniques such as confocal laser scanning microscopy (CLSM) and field emission scanning electron microscope (FE-SEM) [14,16,20-26]. 
The purpose of this study was to evaluate photosensitizing ability of FFF separated from TBF extract by measuring the amount of ROS produced after exposure to lights and to investigate the PDI effect of FFF against $S$. mutans and its biofilm.

\section{Results and Discussion}

\subsection{ROS Production by FFF}

Intracellular ROS productions in the $S$. mutans suspensions added with FFF when exposed to BL (450 nm), yellow light (YL; $590 \mathrm{~nm})$, and red light (RL; $660 \mathrm{~nm})$ were shown in Figure 2a. The fluorescence intensity of the $S$. mutans suspension with FFF exposed to BL ( 5 or $10 \mathrm{~J} / \mathrm{cm}^{2}$ ) was significantly higher than that of YL or RL (Figure 2a), indicating that BL was an appropriate light source to produce ROS by FFF. The fluorescence intensity of the $S$. mutans suspension added with FFF along with D-mannitol when exposed to BL $\left(5\right.$ or $10 \mathrm{~J} / \mathrm{cm}^{2}$ ) was significantly lower than that with FFF only (Figure $2 \mathrm{~b}$ ), suggesting that FFF exposed to BL might produce hydroxyl radicals, which might be then scavenged by D-mannitol.
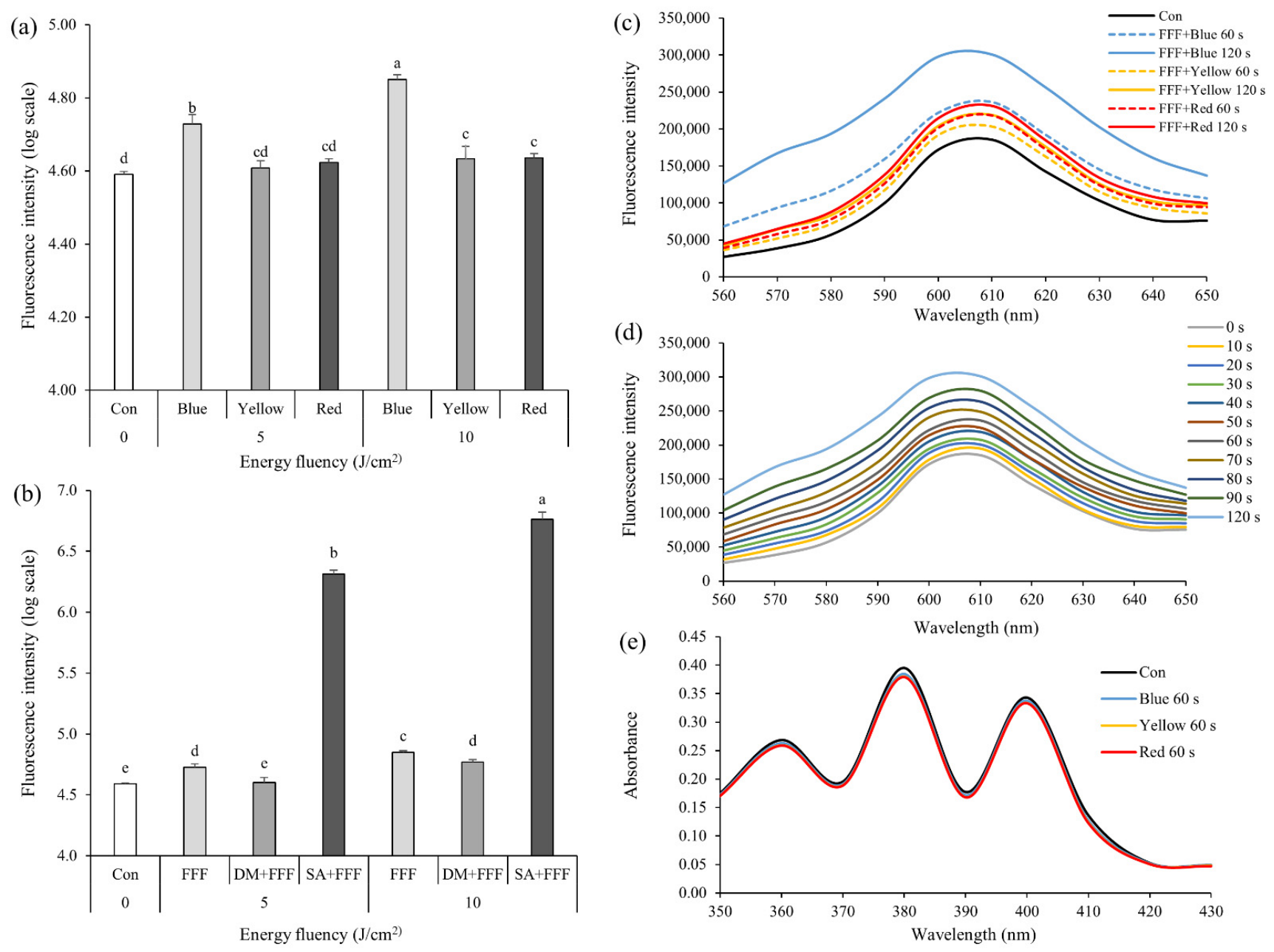

Figure 2. Production of reactive oxygen species (ROS) by fagopyrin F-rich fraction (FFF; final concentration of $5 \mu \mathrm{g} / \mathrm{mL}$ ) from Tartary buckwheat flower extract after exposure to lights. (a) Intracellular ROS production in Streptococcus mutans treated by FFF with different lights. (b) Intracellular ROS production in S. mutans treated by FFF with blue light (5 or $10 \mathrm{~J} / \mathrm{cm}^{2}$ ) with different radical scavengers. DM: D-mannitol (final concentration of $100 \mathrm{mM}$ ). SA: sodium azide (final concentration of $100 \mathrm{mM}$ ). (c) Superoxide production in S. mutans treated by FFF with different lights. (d) Superoxide production in S. mutans treated by FFF with blue light. (e) Singlet oxygen production treated by FFF with different lights. (a-e) Con: control with FFF without irradiation. $(\mathbf{a}, \mathbf{b})$ Different small letters indicate significant differences $(p<0.05$; one-way ANOVA and Duncan's multiple range test). $(\mathbf{a}, \mathbf{b})$ Bars are means \pm standard deviations $(n=3)$. (c-e) Data lines are means $(n=3)$. 
On the other hand, when the $S$. mutans suspension with FFF along with sodium azide $\left(\mathrm{NaN}_{3}\right)$ was exposed to $\mathrm{BL}\left(5\right.$ or $\left.10 \mathrm{~J} / \mathrm{cm}^{2}\right)$, the fluorescence intensity did not decrease as the singlet oxygen might be scavenged by sodium azide, and the fluorescence intensity rapidly increased during exposure to BL (Figure $2 b$ ). This result implies that the fluorescence intensity increases by binding $2^{\prime}, 7^{\prime}$-dichlorofluorescin diacetate (DCFH-DA) to azide radical $\left(\mathrm{N}_{3}{ }^{\bullet}\right)$ derived from $\mathrm{NaN}_{3}$ rather than singlet oxygen produced by FFF [20,27]. That is, when FFF was exposed to BL, singlet oxygen might not be generated or the amount of singlet oxygen might not be enough to be combined with DCFH-DA.

Intracellular superoxide productions in the $S$. mutans suspensions added with FFF when exposed to BL, YL, and RL were shown in Figure 2c. The fluorescence intensity of the $S$. mutans suspension with FFF when exposed to YL or RL for $120 \mathrm{~s}$ was slightly higher than the control (Figure 2c), whereas the intensity of the FFF suspension exposed to BL for $120 \mathrm{~s}$ increased in a time-dependent manner (Figure 2d). Superoxide production by FFF exposed to BL was higher than that exposed to YL or RL. These results were consistent with those measured by DCFH-DA.

When 9,10-anthracenediyl-bis(methylene)dimalonic acid (ABDA) added with FFF was exposed to $\mathrm{BL}, \mathrm{YL}$, or $\mathrm{RL}$, its absorbance, whose reduction indicates more singlet oxygen production, differed little from that of the control, regardless of the wavelength (Figure 2e). However, the previous study observed a rapid decrease in the absorbance when ABDA added with PS such as methylene blue, toluidine blue, and rose bengal was exposed to light [21,28], suggesting these PS may very effectively produce singlet oxygen following the type 2 ROS production mechanism. Thus, our result suggests that FFF exposed to light little produces singlet oxygen.

In summary, ROS production mechanism of FFF exposed to lights might be type 1 . Also, type 1 ROS were more produced when FFF was exposed to BL than YL and RL. Therefore, subsequent PDI experiments were conducted using BL.

\subsection{Photodynamic Inactivation of Planktonic S. mutans}

The colony forming unit (CFU) of $S$. mutans did not significantly decrease after FT (S. mutans suspension treated with FFF (final concentration of $5 \mu \mathrm{g} / \mathrm{mL}$ ) without irradiation), MT (S. mutans suspension in $2.5 \%$ methanol (the same concentration of methanol in the suspension treated with FFF at the final concentration of $5 \mu \mathrm{g} / \mathrm{mL}$ ) with no FFF treatment nor irradiation), or MIT (S. mutans suspension in $2.5 \%$ methanol without FFF, which was exposed to BL of $10 \mathrm{~J} / \mathrm{cm}^{2}$ ) treatment compared to NT (S. mutans suspension with no FFF treatment nor irradiation) (Figure 3a), suggesting $5 \mu \mathrm{g} / \mathrm{mL}$ FFF or $2.5 \%$ methanol (final concentration) in the suspension without BL exposure might not kill S. mutans. The BL exposure $\left(10 \mathrm{~J} / \mathrm{cm}^{2}\right)$ of the suspension without FFF (MIT) did not affect $S$. mutans viability in this study, although BL (400-450 $\mathrm{nm}$ ) is known to have antibacterial effects [20]. Paschoal et al. reported that $S$. mutans was not killed when exposed to BL $(450 \pm 30 \mathrm{~nm} ; 24$, 48 , or $72 \mathrm{~J} / \mathrm{cm}^{2}$ ) without PS treatment [17]. Moreover, S. mutans viability did not decrease when exposed to BL ( $\left.405 \mathrm{~nm} ; 25.4 \mathrm{~J} / \mathrm{cm}^{2}\right)$ without a PS [18]. In this study, S. mutans was exposed to BL ( 5 or $10 \mathrm{~J} / \mathrm{cm}^{2}$ ), in which energy fluences were lower than in the previous studies $[17,18]$. Therefore, it is certain that BL $\left(5\right.$ and $\left.10 \mathrm{~J} / \mathrm{cm}^{2}\right)$ tested in this study does not affect $S$. mutans viability.

When the S. mutans suspension added with FFF was exposed to BL (5 and $\left.10 \mathrm{~J} / \mathrm{cm}^{2}\right)$, CFU in the PDI treatment groups were significantly lower than the NT and FT (Figure 3a). CFU in the $S$. mutans suspension added with FFF when exposed to BL decreased in a dose-dependent and energy fluence-dependent manners. In this study, when S. mutans suspension added with FFF ( $5 \mu \mathrm{g} / \mathrm{mL}$ ) was incubated for $10 \mathrm{~min}$ and then exposed to BL $\left(450 \mathrm{~nm} ; 10 \mathrm{~J} / \mathrm{cm}^{2}\right)$, S. mutans viability decreased by $97.6 \%$ compared to the FT. Lüthi et al. reported that when S. mutans was incubated with hypericin $(10 \mu \mathrm{g} / \mathrm{mL})$ for $30 \mathrm{~min}$ and then exposed to BL (400-505 nm) with energy fluence of 128.4 and $256.8 \mathrm{~J} / \mathrm{cm}^{2}$, S. mutans viability decreased by 99.2 and $99.998 \%$, respectively, compared to the control [4]. Paschoal et al. also reported that when $S$. mutans was incubated with curcumin $(2 \mathrm{mM} ; 736.8 \mu \mathrm{g} / \mathrm{mL})$ 
for $1 \mathrm{~min}$ and then exposed to BL $\left(450 \pm 30 \mathrm{~nm} ; 24 \mathrm{~J} / \mathrm{cm}^{2}\right), S$. mutans viability decreased by $99.13 \%$ compared to the control [17]. However, considering that PS concentrations and energy fluences in the previous studies were higher than those in this study, FFF may have comparable potency to kill S. mutans to other PS. On the other hand, Ribeiro et al. reported that when S. mutans was incubated with riboflavin $(40 \mu \mathrm{g} / \mathrm{mL})$ for $10 \mathrm{~min}$ and exposed to BL ( $\left.455 \pm 20 \mathrm{~nm} ; 32.4 \mathrm{~J} / \mathrm{cm}^{2}\right)$, S. mutans viability decreased by $77.5 \%$ compared to the control [19], in which a smaller decrease in viability of $S$. mutans was observed although a higher PS concentration and a higher energy fluence were applied than in this study.

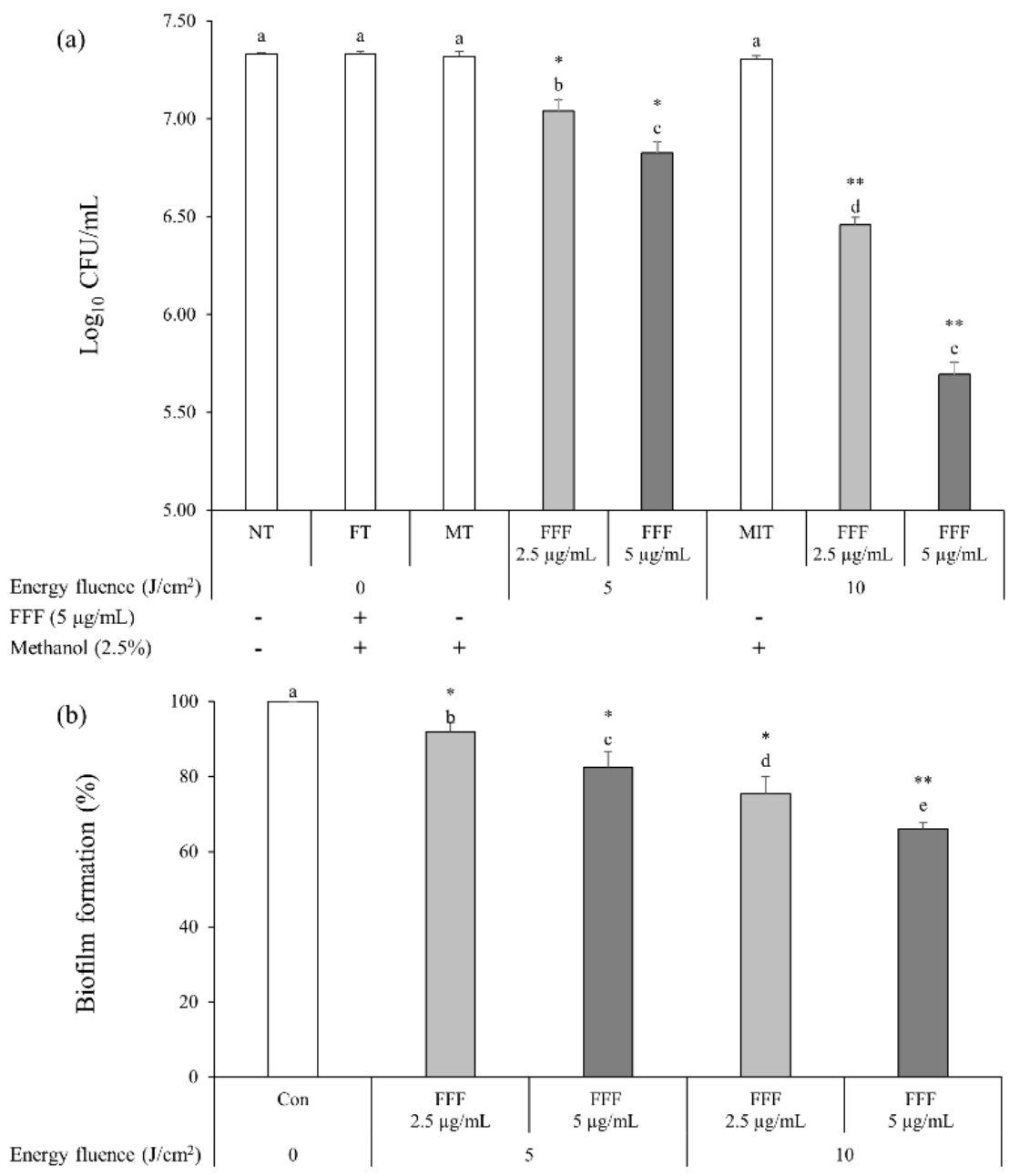

Figure 3. Photodynamic effect of fagopyrin F-rich fraction (FFF) from Tartary buckwheat flower extract against Streptococcus mutans and its biofilm. (a) Inactivation of S.mutans treated with FFF exposed to blue light (BL). NT: S. mutans suspension with no FFF treatment nor irradiation. FT: S. mutans suspension treated with FFF (final concentration of $5 \mu \mathrm{g} / \mathrm{mL}$ ) without irradiation. MT: S. mutans suspension in $2.5 \%$ methanol (the same concentration of methanol in the suspension treated with FFF at the final concentration of $5 \mu \mathrm{g} / \mathrm{mL}$ ) with no FFF treatment nor irradiation. MIT: S. mutans suspension in $2.5 \%$ methanol without FFF, which was exposed to BL $\left(10 \mathrm{~J} / \mathrm{cm}^{2}\right)$. (b) Biofilm formation of S. mutans treated with FFF exposed to BL. Con: control with FFF (final concentration of $5 \mu \mathrm{g} / \mathrm{mL}$ ) without irradiation. $(\mathbf{a}, \mathbf{b})$ Different small letters indicate significant differences $(p<0.05$; one-way ANOVA and Duncan's multiple range test). ${ }^{*}, * *$ Significant difference compared to FT (a) or Con (b) $(p<0.05, p<0.01$; independent $t$-test). Bars are means \pm standard deviations $(n=3)$.

\subsection{Effects of PDI Treatment of FFF on S. mutans Biofilm Formation}

S. mutans biofilm formation in the PDI treatment groups was significantly lower than that in the control (Figure 3b). The S. mutans suspension added with FFF $(5 \mu \mathrm{g} / \mathrm{mL})$ exposed to $\mathrm{BL}\left(10 \mathrm{~J} / \mathrm{cm}^{2}\right)$ had the highest inhibition in the biofilm formation among the 
PDI treatment groups. Inhibition rates of biofilm formation with the PDI treatments of FFF at $2.5 \mu \mathrm{g} / \mathrm{mL}$ exposed to BL of $5 \mathrm{~J} / \mathrm{cm}^{2}$ and FFF at $5 \mu \mathrm{g} / \mathrm{mL}$ exposed to BL of $10 \mathrm{~J} / \mathrm{cm}^{2}$ were the lowest $(11.6 \%)$ and the highest $(34.0 \%)$, respectively, compared to the control (Figure $3 b$ ). In this study, the PDI treatment with a higher concentration of FFF formed less biofilm at the same energy fluence (Figure 3b). However, the PDI treatment with FFF at $2.5 \mu \mathrm{g} / \mathrm{mL}$ exposed to BL of $10 \mathrm{~J} / \mathrm{cm}^{2}$ formed a significantly less biofilm than the PDI treatment with FFF at $5 \mu \mathrm{g} / \mathrm{mL}$ exposed to BL of $5 \mathrm{~J} / \mathrm{cm}^{2}(p<0.05$; Figure $3 \mathrm{~b})$. These results suggest that increased energy fluence might be more efficient than increased FFF concentration in inhibiting $S$. mutans biofilm formation.

In this study, we confirmed for the first time that FF in the FFF, when exposed to BL, exerts antibacterial and antibiofilm effects in $S$. mutans. As previously stated, inactivation of $S$. mutans and biofilm formation by PDI using hypericin was reported [15]. It has been also reported that hypericin has a PDI effect on several gram-positive bacteria $[4,15]$. Thus, further studies are warranted to confirm the PDI effects of FFF on other harmful gram-positive bacteria.

\subsection{Visualization of Antibiofilm Effects of FFF by CLSM}

CLSM was performed to visualize the PDI effects of FFF against S. mutans biofilms (Figure 4). SYTO 9 and propidium iodide dyes were used for staining living cells green and dead cells red, respectively, and confirmed whether bacterial death occurred after the PDI treatment of FFF [29]. The fluorescence images of the NT and FT showed dense green staining indicating live bacteria (Figure 4). However, when the energy fluence increased, this green staining gradually dimmed and red staining gradually increased, indicating bacterial death. These results suggest that the PDI treatment of FFF may be effective in destructuring $S$. mutans biofilms. These observations were similar to CLSM image color changes from previous PDI studies using other PS [21,30].

\subsection{Visualization of Antibiofilm Effect of FFF by FE-SEM}

FE-SEM was used to visualize the PDI effect of FFF against $S$. mutans biofilms (Figure 5). Cell division in S. mutans occurs toward poles of cells and tends not to completely separate; hence the bacteria form chain shapes as they grow [31]. Before the PDI treatment as in the NT and FT, most $S$. mutans looked like short-chains in the biofilm (Figure 5). Namely, S. mutans formed an intact original shape without cell damage. However, after the PDI treatment of FFF, S. mutans cell membranes were destroyed by ROS produced from FFF (Figure 5). These FE-SEM images indicate that the cell membrane, not the intracellular cytoplasm, might be the major site of the damage mediated by ROS derived from FFF. Cell membrane destruction and cytoplasm leakage were clearly observed in the FE-SEM images at 15,000 $\times$ and 100,000 $\times$ magnifications, respectively (Figure 5). Also, S. mutans chain structures collapsed, resulting from cell membrane destruction by ROS from the PDI treatment of FFF. The FE-SEM images also showed a vast $S$. mutans biofilm destruction, as well as significant morphological changes in $S$. mutans chains after the PDI of FFF. This S. mutans biofilm destruction was energy fluence-dependent. Briefly, biofilms after the PDI treatment of FFF exposed to BL of $10 \mathrm{~J} / \mathrm{cm}^{2}$ were more morphologically destroyed than BL of $5 \mathrm{~J} / \mathrm{cm}^{2}$ (Figure 5). These data were consistent with the results described in Section 2.3. Also, the FE-SEM images of $S$. mutans biofilm destroyed by the PDI in this study were similar to those presented in the previous studies [21,23]. 


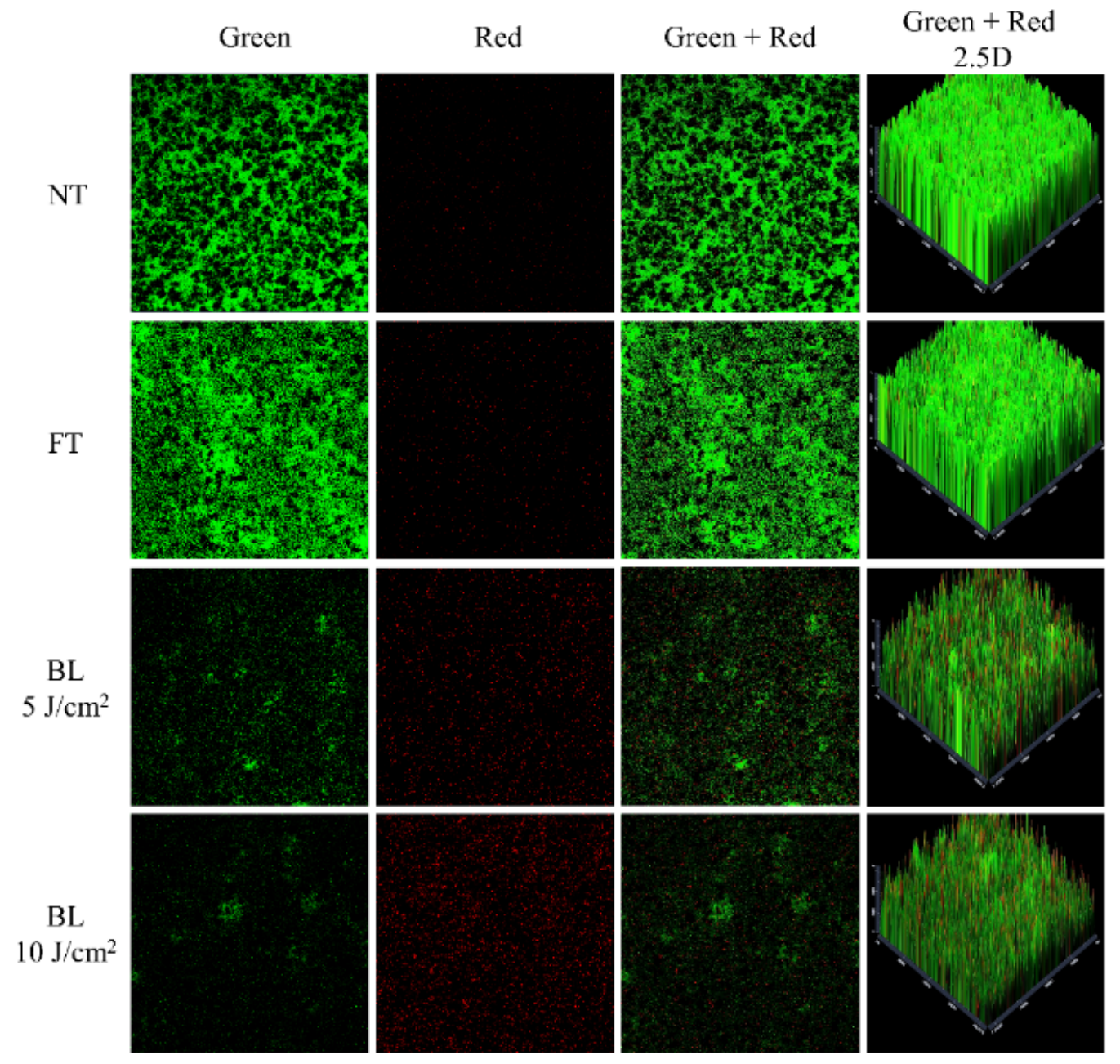

Figure 4. Confocal laser scanning microscopy images of Streptococcus mutans biofilm treated with photodynamic therapy of fagopyrin F-rich fraction (FFF; final concentration of $5 \mu \mathrm{g} / \mathrm{mL}$ ) exposed to blue light (BL). NT: S. mutans biofilm with no FFF treatment nor irradiation. FT: S. mutans biofilm treated with FFF without irradiation.

In general, ROS produced from PDI destroys cell membranes and denatures cellular DNA. Takasaki et al. reported that a PS destroys cell membranes via ROS production after attaching to the cell membrane rather than destroying DNA by intracellular ROS production [32]. ROS produced by PS membrane attachment inactivates the membrane transport system and associated enzymes, thereby inducing lipid peroxidation, which damages the cell membrane structure [32,33]. Esmatabadi et al. reported that after PDImediated cell membrane destruction, cytoplasm contents and metabolites were released from cells, and DNA was damaged [34]. In this study, we observed the destruction and cytoplasmic release of $S$. mutans cell membranes via the PDI treatment of FFF. Similar to other PS, FFF is believed to selectively bind to cytoplasmic membrane components and cause direct cell death by ROS via destruction of the membrane. 


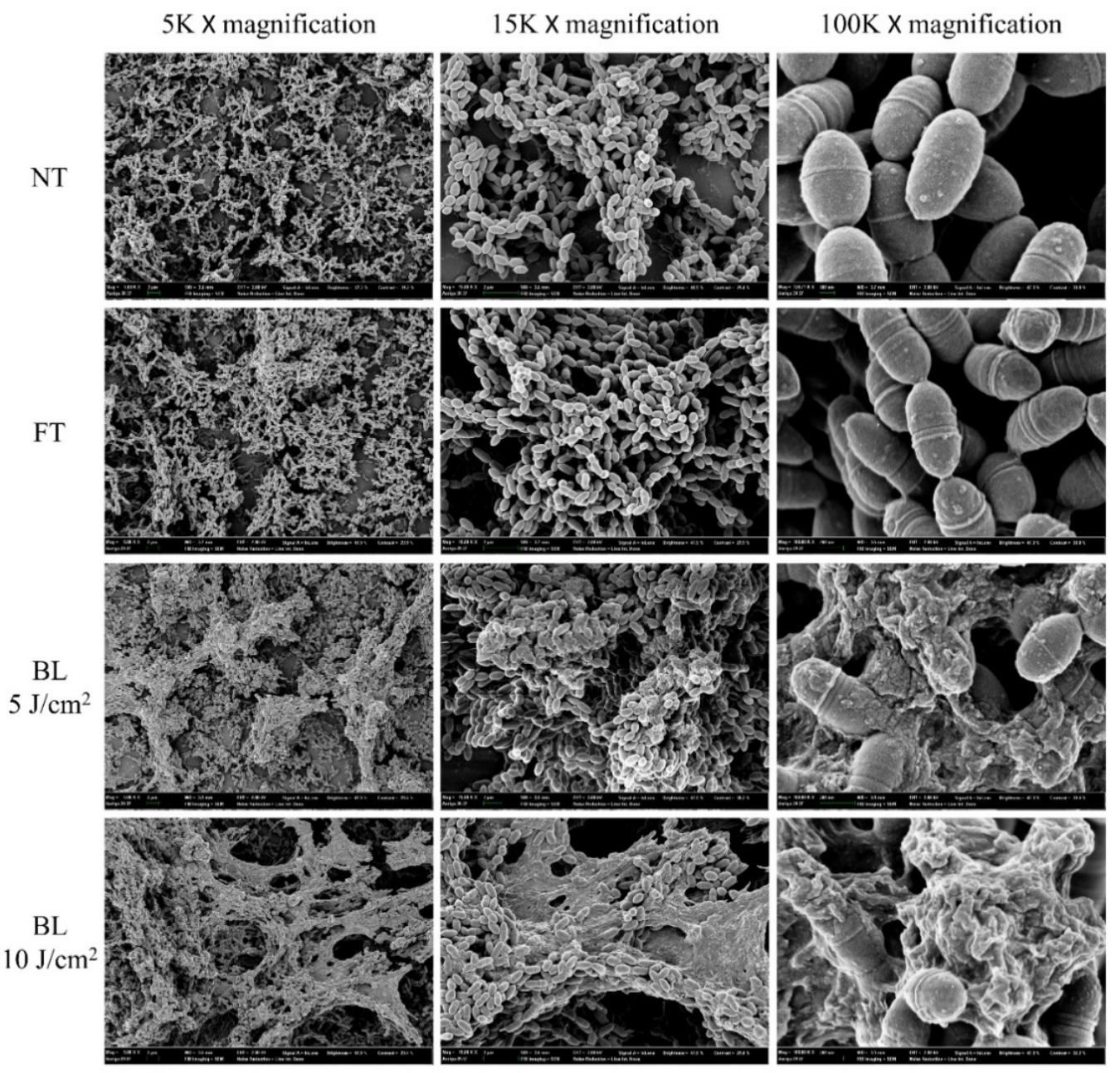

Figure 5. Field emission scanning electron microscope images of Streptococcus mutans biofilm treated with photodynamic therapy of fagopyrin F-rich fraction (FFF; final concentration of $5 \mu \mathrm{g} / \mathrm{mL}$ ) exposed to blue light (BL). NT: S. mutans biofilm with no FFF treatment nor irradiation. FT: S. mutans biofilm treated with FFF without irradiation.

\section{Materials and Methods}

\subsection{Chemicals and Reagents}

Brain heart infusion (BHI) broth was purchased from BD (Becton, Dickinson and Company, Franklin Lakes, NJ, USA). ABDA, acetic acid, agar, crystal violet solution, DCFH-DA, D-mannitol, dihydroethidium (DHE), ethanol, formic acid, glycerol, and sodium azide were purchased from Sigma-Aldrich Co. (St. Louis, MO, USA). Glutaraldehyde, hexamethyldisilazane, osmium tetroxide, paraformaldehyde, and sodium cacodylate buffer (SCB) were purchased from Electron Microscopy Science (EMS) (Hatfield, PA, USA). Methanol and acetonitrile were purchased from J.T. Baker (Phillipsburg, NJ, USA). Phosphate buffer saline (PBS) and LIVE/DEAD ${ }^{\mathrm{TM}}$ Bacterial Viability Kit (L-7012) were purchased from Thermo Fisher Scientific (Waltham, MA, USA).

\subsection{Bacterial Strain and Culture}

S. mutans KCTC 3298 from the Korean Collection for Type Cultures (KCTC, Jeongeup, Korea) was cultured in the $\mathrm{BHI}$ broth at $37^{\circ} \mathrm{C}$. S. mutans stock solution was prepared by inoculating a single colony of bacteria from BHI agar plate into BHI broth $(10 \mathrm{~mL})$ and incubating for $24 \mathrm{~h}$. After incubation, equal volumes of aliquoted bacterial broth of S. mutans and $50 \%$ glycerol were mixed, and the mixture was stored at $-80^{\circ} \mathrm{C}$ as stock. For subsequent experiments, the thawed S. mutans stock was inoculated into BHI broth 
$(1 \%)$ and was cultured for $24 \mathrm{~h}$. The cultured suspension of S. mutans was inoculated into fresh BHI broth $(1 \%)$ and cultured for $24 \mathrm{~h}$. The activated S. mutans $\left(1.1 \times 10^{9} \mathrm{CFU} / \mathrm{mL}\right)$ was used in subsequent experiments.

\subsection{Preparation of FFF and Light Sources}

TBF was collected as described in the previous study [9]. Freeze-dried TBF powder $(500 \mathrm{mg}$ ) was extracted with methanol $(20 \mathrm{~mL})$ in a water bath (BS-11, Lab Companion, Seoul, Korea) at $60{ }^{\circ} \mathrm{C}$ for $60 \mathrm{~min}$. The extract was centrifuged at $1500 \times \mathrm{g}$ for $10 \mathrm{~min}$. The supernatant was filtered through a $0.2 \mu \mathrm{m}$ syringe filter (DISMIC-13JP, Advantec, Tokyo, Japan) and the filtrate was exposed to fluorescent light (400-700 nm; LED Bulb $12 \mathrm{~W}$, Philips Korea, Seoul, Korea) for $2 \mathrm{~h}$ to convert protofagopyrins to fagopyrins. An HPLC system (e2695, Waters, Milford, MA, USA) equipped with a photodiode array detector (2998, Waters, USA) and an Agilent Zorbax Eclipse XDB (250 mm $\times 4.6 \mathrm{~mm}, 5 \mu \mathrm{m}$; Agilent, Palo Alto, CA, USA) column was used to separate FFF from the TBF extract. Mobile phases were $0.1 \%$ formic acid in distilled water (A) and $0.1 \%$ formic acid in acetonitrile (B). Flow rate was $1.2 \mathrm{~mL} / \mathrm{min}$. Gradient elution was set as follows: $60 \% \mathrm{~B}$ in $0-2 \mathrm{~min}, 60-100 \%$ B in $2-8 \mathrm{~min}, 100 \%$ B in $8-9.5 \mathrm{~min}, 100-60 \%$ B in $9.5-10 \mathrm{~min}$, and $60 \%$ B in $10-11 \mathrm{~min}$. Column temperature was $50{ }^{\circ} \mathrm{C}$. Injection volume was $100 \mu \mathrm{L}$. The fraction (FFF) eluted between 9.0 and $10.0 \mathrm{~min}$ of retention time, at which fagopyrins detected at $590 \mathrm{~nm}$ were collected mostly, were dried using a centrifugal vacuum concentrator (VC 2200, Labogene, Seoul, Korea). The FFF powder was dissolved in methanol and stored at $-80^{\circ} \mathrm{C}$ for subsequent experiments. FF accounted for $92.33 \pm 0.08 \%(n=3)$ in the FFF, when calculated based on the peak areas obtained by HPLC-PDA and UPLC-MS/MS [3].

BL (450 nm; ABI 12 W Blue LED, ABI, Indianapolis, IN, USA), YL (590 nm; 15 W PI200, Bissol LED, Seoul, Korea), and RL (660 nm; ABI 12 W DEEP RED LED, ABI) were used in this study to find a suitable wavelength to activate FFF as a PS. Output powers of light sources were expressed as power density $\left(\mathrm{W} / \mathrm{cm}^{2}\right)$ and energy fluence $\left(\mathrm{J} / \mathrm{cm}^{2}\right)$, which were calculated as follows [23]:

Power density $\left(\mathrm{W} / \mathrm{cm}^{2}\right)=$ output power $(\mathrm{W}) /$ area $\left(\mathrm{cm}^{2}\right)$

Energy fluence $\left(\mathrm{J} / \mathrm{cm}^{2}\right)=$ power density $\left(\mathrm{W} / \mathrm{cm}^{2}\right) \times$ exposure time $(\mathrm{s})$

\subsection{ROS Production by FFF}

\subsubsection{Intracellular ROS Production}

Intracellular ROS produced in FFF-incorporated S. mutans suspension exposed to light was measured by fluorescence spectroscopy using DCFH-DA as described in previous studies with some modifications $[20,27]$. The cultured $S$. mutans suspension was diluted with PBS to $10^{8} \mathrm{CFU} / \mathrm{mL}$. The suspension was incubated with DCFH-DA (final concentration of $5 \mu \mathrm{M}$ ) at $37^{\circ} \mathrm{C}$ for $30 \mathrm{~min}$ in the dark. FFF (final concentration of $5 \mu \mathrm{g} / \mathrm{mL}$ ) was added to the suspension, which was then treated with D-mannitol (type 1 ROS scavenger; final concentration of $100 \mathrm{mM}$ ) or sodium azide (type 2 ROS scavenger; final concentration of $100 \mathrm{mM}$ ) or not treated. The suspension was exposed to BL, YL, or RL (5 or $\left.10 \mathrm{~J} / \mathrm{cm}^{2}\right)$. After the irradiation, fluorescence intensity was measured by SpectraMax iD3 (Molecular Devices, San Jose, CA, USA) at an excitation wavelength of $485 \mathrm{~nm}$ and an emission wavelength of $525 \mathrm{~nm}$. Control was treated with the same final concentration of FFF without exposure to light.

\subsubsection{Superoxide Production}

Intracellular superoxide produced in FFF-incorporated S. mutans suspension exposed to light was measured by fluorescence spectroscopy using DHE as described in previous studies with some modifications $[35,36]$. The cultured $S$. mutans suspension was diluted with PBS to $10^{8} \mathrm{CFU} / \mathrm{mL}$. DHE (final concentration of $5 \mathrm{mM}$ ) was added to the suspension. The suspension was incubated at $37^{\circ} \mathrm{C}$ for $30 \mathrm{~min}$ in the dark. FFF (final concentration of $5 \mu \mathrm{g} / \mathrm{mL}$ ) was added to the suspension, which was then incubated at $37^{\circ} \mathrm{C}$ for $15 \mathrm{~min}$ in the dark. After incubation, fluorescence intensity (excitation wavelength: $510 \mathrm{~nm}$; emission 
spectrum: 560-650 nm) of the suspension was measured before exposure to light and every $10 \mathrm{~s}$ afterwards for $120 \mathrm{~s}$ while exposing the suspension to light (BL, YL, or RL) of $0.16 \mathrm{~W} / \mathrm{cm}^{2}$. Fluorescence intensity was measured using SpectraMax iD3 (Molecular Devices). Control was treated with the same final concentration of FFF without exposure to light.

\subsubsection{Singlet Oxygen Detection}

Singlet oxygen produced when FFF was exposed to light was measured by spectrophotometry using ABDA as described in a previous study with some modification [37].

ABDA (final concentration of $20 \mu \mathrm{M}$ ) and FFF (final concentration of $5 \mu \mathrm{g} / \mathrm{mL}$ ) in PBS were added in 96-well plate (SPL, Pocheon, Korea). The absorbance spectrum (350-430 nm) was measured using SpectraMax iD3 (Molecular Devices). After measurement of the initial absorbance spectrum without exposure to light, it was measured every $10 \mathrm{~s}$ for $60 \mathrm{~s}$ while exposing the wells to light (BL, YL, or RL) of $0.16 \mathrm{~W} / \mathrm{cm}^{2}$. Control was treated with the same final concentration of FFF without exposure to light.

\subsection{Effect of S. mutans Inactivation with PDI Treatment of FFF}

The effect of $S$. mutans inactivation with PDI treatment of FFF was performed as described in a previous study with some modification [21]. The PDI effect of FFF against S. mutans was determined using the plate count method. The cultured S. mutans suspension was diluted with PBS to $10^{8} \mathrm{CFU} / \mathrm{mL}$. The suspension with FFF (final concentration of 2.5 or $5 \mu \mathrm{g} / \mathrm{mL}$ ) was incubated at $37^{\circ} \mathrm{C}$ for $10 \mathrm{~min}$ in the dark. Then suspensions were exposed to BL ( 5 or $10 \mathrm{~J} / \mathrm{cm}^{2}$ ). After exposure, 10 -fold serial dilutions in PBS were performed, and $100 \mu \mathrm{L}$ of the suspensions were spread on BHI agar plates. After incubating for $48 \mathrm{~h}$, the number of single colonies was counted. To figure out any intervention other than the PDI the following treatments were also tested: NT, FT, MT, and MIT.

\subsection{Inhibition of S. mutans Biofilm Formation with PDI Treatment of FFF}

Inhibition of $S$. mutans biofilm formation with PDI treatment of FFF was spectrophotometrically determined using crystal violet dye as described in the previous study with some modification [14]. The cultured S. mutans suspension was diluted to $10^{8} \mathrm{CFU} / \mathrm{mL}$ with fresh BHI broth containing $5 \%$ sucrose. The suspension $(1 \mathrm{~mL})$ was added to each well of a sterile and flat 24-well plate (SPL), and FFF (final concentration of $2.5 \mathrm{or} 5 \mu \mathrm{g} / \mathrm{mL}$ ) was added into the suspension. The suspension was incubated at $37^{\circ} \mathrm{C}$ for $15 \mathrm{~min}$ in the dark. After incubation, the suspension was exposed to BL ( 5 or $\left.10 \mathrm{~J} / \mathrm{cm}^{2}\right)$. The PDI-treated suspension was incubated to form biofilm at $37^{\circ} \mathrm{C}$ for $24 \mathrm{~h}$ in the dark. The medium was decanted and gently washed twice with $1 \mathrm{~mL}$ PBS to remove loosely bound biofilm and unbound planktonic $S$. mutans. Biofilm was stained with $1 \mathrm{~mL} 0.1 \%$ crystal violet for 15 min on a well plate shaker (MX-M, DLAB, Riverside, CA, USA) at $300 \mathrm{rpm}$ and room temperature (RT). The crystal violet dye was removed, and the biofilm was gently washed twice with $1 \mathrm{~mL}$ PBS. The stained biofilm was air-dried at RT for $15 \mathrm{~min}$. After drying, $600 \mu \mathrm{L} \mathrm{33 \%}$ acetic acid was added to dissolve the stained biofilm. The suspension was dissolved for $10 \mathrm{~min}$ on a well-plate shaker (DLAB, USA) at $300 \mathrm{rpm}$ and RT. The absorbance of the dissolved biofilm suspension was measured using a SpectraMax iD3 (Molecular Devices) at $570 \mathrm{~nm}$. Control was treated with the same final concentrations of FFF without exposure to BL. Biofilm formation level was expressed as the percentage of the control.

\subsection{Visualization in PDI Effects of FFF against S. mutans Biofilm}

\subsubsection{CLSM}

The $S$. mutans suspension was diluted with fresh BHI broth containing $5 \%$ sucrose to $10^{6} \mathrm{CFU} / \mathrm{mL}$. The suspension $(3 \mathrm{~mL})$ in a sterile confocal dish (SPL) was incubated at $37^{\circ} \mathrm{C}$ for $24 \mathrm{~h}$ to form $S$. mutans biofilm. The medium was decanted and gently washed twice with $1 \mathrm{~mL}$ PBS to remove loosely bound biofilm and unbound planktonic $S$. mutans. 
One $\mathrm{mL}$ FFF (final concentration of $5 \mu \mathrm{g} / \mathrm{mL}$ ) in PBS was added to the biofilm in the confocal dish. The suspension was exposed to BL $\left(5\right.$ or $\left.10 \mathrm{~J} / \mathrm{cm}^{2}\right)$. The suspension was removed to obtain the biofilm, which was then gently washed twice with $1 \mathrm{~mL}$ PBS. Biofilm was stained using LIVE/DEAD ${ }^{\mathrm{TM}}$ Bacterial Viability Kit (SYTO 9 and propidium iodide dye) according to the manufacturer's instruction. The biofilm with staining solution was incubated in the dark at $37^{\circ} \mathrm{C}$ for $1 \mathrm{~h}$. The staining solution was removed and $100 \mu \mathrm{L}$ PBS was added to prevent drying of biofilm. Fluorescence images were observed using CLSM (LSM710, Carl Zeiss, Oberkochen, Germany) at fluorescences of green (excitation wavelength: $488 \mathrm{~nm}$; emission wavelength: $516 \mathrm{~nm}$ ) and red (excitation wavelength: $543 \mathrm{~nm}$; emission wavelength: $589 \mathrm{~nm}$ ) under 40 times magnification. Control was treated with the same final concentrations of FFF without exposure to BL.

\subsubsection{FE-SEM}

The $S$. mutans suspension was diluted to $10^{6} \mathrm{CFU} / \mathrm{mL}$ in fresh BHI broth containing $5 \%$ sucrose, and the suspension $(3 \mathrm{~mL})$ was incubated to form biofilm of $S$. mutans on glass coverslips ( $24 \times 24 \mathrm{~mm}$, Paul Marienfield, Lauda-Königshofen, Germany) in 6-well plates (SPL) at $37^{\circ} \mathrm{C}$ for $36 \mathrm{~h}$. After biofilm formation on the coverslip, the medium was decanted, and the well was gently washed twice with $1 \mathrm{~mL}$ of PBS to remove loosely bound biofilm and unbound planktonic $S$. mutans. One $\mathrm{mL}$ FFF (final concentration of $5 \mu \mathrm{g} / \mathrm{mL}$ ) in PBS was added into each well, and the suspension was incubated at $37^{\circ} \mathrm{C}$ for $5 \mathrm{~min}$ in the dark. After incubation, the suspension was exposed to BL (5 or $\left.10 \mathrm{~J} / \mathrm{cm}^{2}\right)$. The suspension with FFF was decanted, and the biofilm on the coverslip was gently washed twice with $1 \mathrm{~mL}$ PBS. For primary fixation, the biofilm on the coverslip was soaked for $4 \mathrm{~h}$ in Karnovsky fixative containing $2 \%$ glutaraldehyde and $2 \%$ paraformaldehyde in $0.05 \mathrm{M}$ SCB. The coverslip was washed three times with $0.05 \mathrm{M}$ SCB for $5 \mathrm{~min}$ at each time. Post fixation was conducted using $1 \%$ osmium tetroxide in $0.1 \mathrm{M} \mathrm{SCB}$ at $4{ }^{\circ} \mathrm{C}$ for $1 \mathrm{~h}$. After fixation, the coverslip was washed three times with distilled water for $5 \mathrm{~min}$ at each time and dehydrated in a series of ethanol solutions (30\%, 50\%, 70\%, 80\%, 90\%, and 100\%) for $10 \mathrm{~min}$ each. The coverslip was soaked in hexamethyldisilazane for $10 \mathrm{~min}$ for specimen drying, and then the coverslip was put in a vacuum desiccator for $24 \mathrm{~h}$. After drying, the coverslip was mounted on stubs (EMS) and was coated with platinum by EM ACE 200 (Leica, Wetzlar, Germany). Biofilm images on the coverslip were obtained using FE-SEM (AURIGA, Carl Zeiss, Oberkochen, Germany). Control was treated with the same final concentrations of FFF without exposure to BL.

\subsection{Statistics}

All experiments were conducted in triplicate except for CLSM and FE-SEM. Statistical analysis was conducted by Student's $t$-test and one-way analysis of variance (ANOVA) with Duncan's multiple range test $(p<0.05)$ using SPSS 23.0 software (IBM, Armonk, NY, USA).

\section{Conclusions}

This study demonstrated that FFF when exposed to BL (450 nm) produced ROS, and the ROS production of FFF was on the basis of the type 1 mechanism. Furthermore, $S$. mutans and its biofilm were destroyed by ROS produced by PDI of FFF. It was elucidated that PDI with FFF $(5 \mu \mathrm{g} / \mathrm{mL})$ exposed to BL $\left(10 \mathrm{~J} / \mathrm{cm}^{2}\right)$ destroyed $S$. mutans biofilms, which were visually confirmed by CLSM and FE-SEM. This study demonstrated for the first time that FFF, present in buckwheat plants, is a potent PS and can be applied to PDI. Although the PDI treatment of FFF was conducted at lower energy fluences of BL and lower concentrations than other PS, PDI effect of FFF against $S$. mutans was similar to curcumin and hypericin and was stronger than riboflavin. Thus, FFF might be a more effective PS for PDI against $S$. mutans than commonly used PS. Further studies would be needed to investigate whether the PDI of FFF can be applied to other gram-positive bacteria and tumors. 
Author Contributions: Conceptualization, J.K., S.K., K.L., R.H.K. and K.T.H.; methodology, J.K., S.K. and K.L.; validation, J.K.; formal analysis, J.K.; investigation, J.K.; data curation, J.K. and K.L.; writing-original draft preparation, J.K.; writing—review and editing, S.K., R.H.K. and K.T.H.; visualization, J.K.; supervision, K.T.H. All authors have read and agreed to the published version of the manuscript.

Funding: This research received no external funding.

Institutional Review Board Statement: Not applicable.

Informed Consent Statement: Not applicable.

Data Availability Statement: Not applicable.

Conflicts of Interest: The authors declare no conflict of interest.

\section{References}

1. Benković, E.T.; Kreft, S. Fagopyrins and protofagopyrins: Detection, analysis, and potential phototoxicity in buckwheat. J. Agric. Food. Chem. 2015, 63, 5715-5724. [CrossRef]

2. Ahmed, A.; Khalid, N.; Ahmad, A.; Abbasi, N.A.; Latif, M.S.Z.; Randhawa, M.A. Phytochemicals and biofunctional properties of buckwheat: A review. J. Agric. Sci. 2014, 152, 349-369. [CrossRef]

3. Kim, J.; Kim, S.; Hwang, K.T. Determination and photochemical conversion of protofagopyrins and fagopyrins in buckwheat plants. J. Food Compos. Anal. 2021, 100, 103894. [CrossRef]

4. Lüthi, M.; Gyenge, E.B.; Engstrüm, M.; Bredell, M.; Grätz, K.; Walt, H.; Gmür, R.; Maake, C. Hypericin-and mTHPC-mediated photodynamic therapy for the treatment of cariogenic bacteria. Med. Laser Appl. 2009, 24, 227-236. [CrossRef]

5. Bhatta, A.K.; Keyal, U.; Wang, X.L. Photodynamic therapy for onychomycosis: A systematic review. Photodiagn. Photodyn. Ther. 2016, 15, 228-235. [CrossRef] [PubMed]

6. Jendželovská, Z.; Jendželovský, R.; Kuchárová, B.; Fedoročko, P. Hypericin in the light and in the dark: Two sides of the same coin. Front. Plant Sci. 2016, 7, 560. [CrossRef]

7. Stojilkovski, K.; Glavač, N.K.; Kreft, S.; Kreft, I. Fagopyrin and flavonoid contents in common, Tartary, and cymosum buckwheat. J. Food Compos. Anal. 2013, 32, 126-130. [CrossRef]

8. Benković, E.T.; Žigon, D.; Friedrich, M.; Plavec, J.; Kreft, S. Isolation, analysis and structures of phototoxic fagopyrins from buckwheat. Food Chem. 2014, 143, 432-439. [CrossRef] [PubMed]

9. Kim, J.; Hwang, K.T. Fagopyrins in different parts of common buckwheat (Fagopyrum esculentum) and Tartary buckwheat (F. tataricum) during growth. J. Food Compos. Anal. 2020, 86, 103354. [CrossRef]

10. Kwiatkowski, S.; Knap, B.; Przystupski, D.; Saczko, J.; Kędzierska, E.; Knap-Czop, K.; Kotlińska, J.; Michel, O.; Kotowski, K.; Kulbacka, J. Photodynamic therapy-mechanisms, photosensitizers and combinations. Biomed. Pharmacother. 2018, 106, 1098-1107. [CrossRef]

11. Oniszczuk, A.; Wojtunik-Kulesza, K.A.; Oniszczuk, T.; Kasprzak, K. The potential of photodynamic therapy (PDT)—Experimental investigations and clinical use. Biomed. Pharmacother. 2016, 83, 912-929. [CrossRef]

12. Plaetzer, K.; Kiesslich, T.; Verwanger, T.; Krammer, B. The modes of cell death induced by PDT: An overview. Med. Laser Appl. 2003, 18, 7-19. [CrossRef]

13. Bacellar, I.O.; Tsubone, T.M.; Pavani, C.; Baptista, M.S. Photodynamic efficiency: From molecular photochemistry to cell death. Int. J. Mol. Sci. 2015, 16, 20523-20559. [CrossRef] [PubMed]

14. Beytollahi, L.; Pourhajibagher, M.; Chiniforush, N.; Ghorbanzadeh, R.; Raoofian, R.; Pourakbari, B.; Bahador, A. The efficacy of photodynamic and photothermal therapy on biofilm formation of Streptococcus mutans: An in vitro study. Photodiagn. Photodyn. Ther. 2017, 17, 56-60. [CrossRef]

15. Ghorbani, J.; Rahban, D.; Aghamiri, S.; Teymouri, A.; Bahador, A. Photosensitizers in antibacterial photodynamic therapy: An overview. Laser Ther. 2018, 27, 293-302. [CrossRef]

16. Garcia, M.T.; Pereira, A.H.C.; Figueiredo-Godoi, L.M.A.; Jorge, A.O.C.; Strixino, J.F.; Junqueira, J.C. Photodynamic therapy mediated by chlorin-type photosensitizers against Streptococcus mutans biofilms. Photodiagn. Photodyn. Ther. 2018, 24, 256-261. [CrossRef] [PubMed]

17. Paschoal, M.A.; Tonon, C.C.; Spolidório, D.M.; Bagnato, V.S.; Giusti, J.S.; Santos-Pinto, L. Photodynamic potential of curcumin and blue LED against Streptococcus mutans in a planktonic culture. Photodiagn. Photodyn. Ther. 2013, 10, 313-319. [CrossRef]

18. Lee, H.J.; Kang, S.M.; Jeong, S.H.; Chung, K.H.; Kim, B.I. Antibacterial photodynamic therapy with curcumin and Curcuma xanthorrhiza extract against Streptococcus mutans. Photodiagn. Photodyn. Ther. 2017, 20, 116-119. [CrossRef] [PubMed]

19. Ribeiro, M.S.; de Melo, L.S.; Farooq, S.; Baptista, A.; Kato, I.T.; Núnez, S.C.; de Araujo, R.E. Photodynamic inactivation assisted by localized surface plasmon resonance of silver nanoparticles: In vitro evaluation on Escherichia coli and Streptococcus mutans. Photodiagn. Photodyn. Ther. 2018, 22, 191-196. [CrossRef]

20. Misba, L.; Kulshrestha, S.; Khan, A.U. Antibiofilm action of a toluidine blue O-silver nanoparticle conjugate on Streptococcus mutans: A mechanism of type I photodynamic therapy. Biofouling 2016, 32, 313-328. [CrossRef] [PubMed] 
21. Misba, L.; Zaidi, S.; Khan, A.U. Efficacy of photodynamic therapy against Streptococcus mutans biofilm: Role of singlet oxygen. J. Photochem. Photobiol. B 2018, 183, 16-21. [CrossRef]

22. Fumes, A.C.; da Silva Telles, P.D.; Corona, S.A.M.; Borsatto, M.C. Effect of aPDT on Streptococcus mutans and Candida albicans present in the dental biofilm: Systematic review. Photodiagn. Photodyn. Ther. 2018, 21, 363-366. [CrossRef]

23. Wang, S.; Huang, Q.; Liu, X.; Li, Z.; Yang, H.; Lu, Z. Rapid antibiofilm effect of Ag/ZnO nanocomposites assisted by dental LED curing light against facultative anaerobic oral pathogen Streptococcus mutans. ACS Biomater. Sci. Eng. 2019, 5, 2030-2040. [CrossRef]

24. Zanin, I.C.J.; Goncalves, R.B.; Junior, A.B.; Hope, C.K.; Pratten, J. Susceptibility of Streptococcus mutans biofilms to photodynamic therapy: An in vitro study. J. Antimicrob. Chemother. 2005, 56, 324-330. [CrossRef]

25. Metcalf, D.; Robinson, C.; Devine, D.; Wood, S. Enhancement of erythrosine-mediated photodynamic therapy of Streptococcus mutans biofilms by light fractionation. J. Antimicrob. Chemother. 2006, 58, 190-192. [CrossRef]

26. Wood, S.; Metcalf, D.; Devine, D.; Robinson, C. Erythrosine is a potential photosensitizer for the photodynamic therapy of oral plaque biofilms. J. Antimicrob. Chemother. 2006, 57, 680-684. [CrossRef] [PubMed]

27. Bilski, P.; Belanger, A.G.; Chignell, C.F. Photosensitized oxidation of $2^{\prime}, 7^{\prime}$-dichlorofluorescin: Singlet oxygen does not contribute to the formation of fluorescent oxidation product $2^{\prime}$, 7'-dichlorofluorescein. Free Radic. Biol. Med. 2002, 33, 938-946. [CrossRef]

28. Entradas, T.; Waldron, S.; Volk, M. The detection sensitivity of commonly used singlet oxygen probes in aqueous environments. J. Photochem. Photobiol. B 2020, 204, 111787. [CrossRef] [PubMed]

29. Klinger-Strobel, M.; Ernst, J.; Lautenschläger, C.; Pletz, M.W.; Fischer, D.; Makarewicz, O. A blue fluorescent labeling technique utilizing micro-and nanoparticles for tracking in LIVE/DEAD ${ }^{\circledR}$ stained pathogenic biofilms of Staphylococcus aureus and Burkholderia cepacia. Int. J. Nanomed. 2016, 11, 575.

30. Lee, Y.H.; Park, H.W.; Lee, J.H.; Seo, H.W.; Lee, S.Y. The photodynamic therapy on Streptococcus mutans biofilms using erythrosine and dental halogen curing unit. Int. J. Oral Sci. 2012, 4, 196-201. [CrossRef]

31. Li, Y.; Liu, Z.; Zhang, Y.; Su, Q.P.; Xue, B.; Shao, S.; Zhu, Y.; Xu, X.; Wei, S.; Sun, Y. Live-cell and super-resolution imaging reveal that the distribution of wall-associated protein A is correlated with the cell chain integrity of Streptococcus mutans. Mol. Oral Microbiol. 2015, 30, 376-383. [CrossRef]

32. Takasaki, A.A.; Aoki, A.; Mizutani, K.; Schwarz, F.; Sculean, A.; Wang, C.Y.; Koshy, G.; Romanos, G.; Ishikawa, I.; Izumi, Y. Application of antimicrobial photodynamic therapy in periodontal and peri-implant diseases. Periodontology 2000 2009, 51, 109-140. [CrossRef]

33. Gursoy, H.; Ozcakir-Tomruk, C.; Tanalp, J.; Yılmaz, S. Photodynamic therapy in dentistry: A literature review. Clin. Oral Investig. 2013, 17, 1113-1125. [CrossRef]

34. Esmatabadi, M.D.; Bozorgmehr, A.; Hajjari, S.N.; Sombolestani, A.S.; Malekshahi, Z.V.; Sadeghizadeh, M. Review of new insights into antimicrobial agents. Cell. Mol. Biol. (Noisy-le-grand) 2017, 63, 40-48. [CrossRef] [PubMed]

35. Zhang, Y.; Dai, M.; Yuan, Z. Methods for the detection of reactive oxygen species. Anal. Methods 2018, 10, 4625-4638. [CrossRef]

36. Li, M.; Mai, B.; Wang, A.; Gao, Y.; Wang, X.; Liu, X.; Song, S.; Liu, Q.; Wei, S.; Wang, P. Photodynamic antimicrobial chemotherapy with cationic phthalocyanines against Escherichia coli planktonic and biofilm cultures. RSC Adv. 2017, 7, 40734-40744. [CrossRef]

37. Qian, H.S.; Guo, H.C.; Ho, P.C.L.; Mahendran, R.; Zhang, Y. Mesoporous-silica-coated up-conversion fluorescent nanoparticles for photodynamic therapy. Small 2009, 5, 2285-2290. [CrossRef] 